\title{
COMMUNICATIONS
}

\section{THE FELLOW EYE IN ACUTE CLOSED-ANGLE GLAUCOMA*}

\author{
BY \\ W. E. S. BAIN \\ Glaucoma Clinic, Institute of Ophthalmology, University of London
}

THIS PAPER deals with a series of 200 cases of acute unilateral closed-angle glaucoma, which were examined with a view to establishing a basis for assessing the treatment of the fellow eye.

The investigation of a series of over 3,000 cases of glaucoma of all types at the Glaucoma Clinic of the Institute of Ophthalmology has shown that miotic treatment is no sure guard against the occurrence of an acute attack in the second eye. A patient on miotic therapy may be relieved of his symptoms, for example, by pilocarpine 1 per cent. thrice daily, and yet may have a pathological rise of tension under provocative tests. Consequently such a person is in an unsafe situation; he may get an acute attack in this eye in a moment of vasomotor instability, or he may develop chronic closedangle glaucoma with eventual peripheral anterior synechiae and cupping of the optic disc.

Of recent years, a plea for peripheral iridectomy as a treatment for very early closed-angle glaucoma and as a prophylactic measure has been ably put by Chandler (1952), Chandler and Trotter (1955), and by Barkan (1937, $1938,1939,1954)$. These authors have clearly defined the indications and contra-indications for this relatively simple procedure.

For the purposes of this investigation, acute closed-angle glaucoma has been defined as an attack of tension in this type of the disease sufficiently severe to warrant an intensive course of treatment with eserine on arrival at the hospital. Similarly, the term "bilateral onset", which appears in some of the Tables, refers to those cases which arrived at hospital with both eyes affected.

Of these 200 cases, 110 come from the files of the Institute of Ophthalmology, and ninety from those of the Westminster Branch of Moorfields.

\section{Material}

The average age of all the patients in the series was 59 years (range 87-27). 45 (29 per cent.) were men and 155 (71 per cent.) were women, a sex distribution which agrees with that in other published series.

Of the cases not subjected to operation, 122 were followed-up for 5 years or less, 37 for 5 to 10 years, and only seventeen for more than 10 years. Three of the 
Institute patients are known to have died; those from the hospital files were all alive at the end of 1955 .

With an average age of 58.4 , it seems likely that some patients do not live long enough for the second eye to become affected, and the question arises whether glaucomatous subjects have a higher mortality than the rest of the population. Bennett (1955) published an interesting survey which sheds some light on this matter. He compared the mortality for all cases of glaucoma with that for the rest of the local population and found no significant difference between them.

The second eye may undergo an obvious acute attack or prodromal signs and symptoms may occur. For the purposes of this paper these signs have been defined as:

(i) a clear history of rainbows round lights, blurring of the vision, and pain in or around the eye,

(ii) a raised ocular tension found on routine tonometry,

(iii) positive provocative tests, with or without symptoms.

The cases derived from the Institute have had provocative tests, but those from the hospital have not.

Ten of the Institute cases out of sixty in which the second eye was symptom-free have shown positive provocative tests but have not complained in any way of their apparently normal eye. The dark-room test was the usual provocative test employed; it is generally thought to be positive in 60 per cent. of cases of closedangle glaucoma, but recent work shows that this is probably too high an estimate.

This lack of reliablility of the dark-room test suggests that the proportion of ten out of sixty cases is too low; moreover, no provocative tests were applied to the hospital series, and it seems at least probable that they would also show a proportion of positive results in apparently normal eyes. It seems therefore that the figures for prodromal symptoms submitted below may be too low, and that a markedly higher number of patients would have been placed in this category if they had been submitted to a provocative test of 100 per cent. reliability.

Table I shows that, of these 200 cases, only seven had a prophylactic operation on the second eye, while seventeen patients had both eyes affected simultaneously. In none of the eyes subjected to surgery did a straightforward primary angleclosure glaucoma occur. This leaves 193 cases, and in these the second eye has been involved in 102 (53 per cent.).

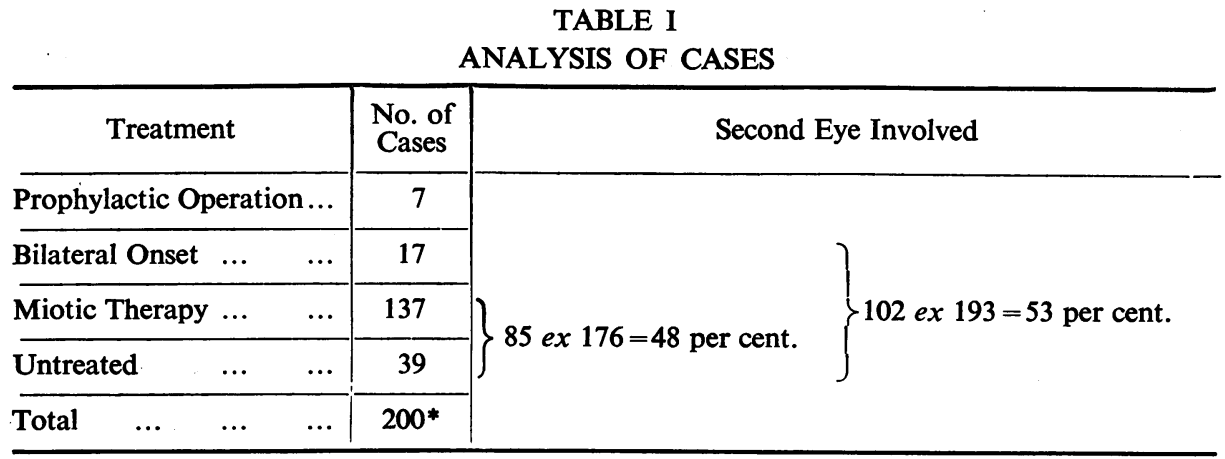

* Average age 58.4 yrs. 
Excluding those patients who suffered a simultaneous onset in both eyes, the second eye was involved in 85 out of 176 (48 per cent.).

TABLE II

FATE OF FELLOW EYE

\begin{tabular}{|c|c|c|}
\hline Cases & No. & Percent \\
\hline Acute Attacks ... & 50 & $28(35)$ \\
\hline Prodromal Symptoms . & 35 & $20(18)$ \\
\hline No Symptoms yet & 91 & $52(47)$ \\
\hline Total $\quad \ldots$ & 176 & $100(100)$ \\
\hline
\end{tabular}
tion were excluded because none had an acute attack or "prodromal symptoms" of the precise kind defined above.

On the other hand, fifty of the remainder, including both treated and untreated cases, had an acute attack in the second eye. Even more striking is the fact that of the 137 patients treated with miotics, 29 (21 per cent.) had a second acute attack, and 25 (18 per cent.), developed "prodromal symptoms" (Table III).

TABLE III

RESULTS OF TREATMENT

\begin{tabular}{|c|c|c|c|c|c|c|c|}
\hline \multicolumn{4}{|c|}{ Treatment } & 2nd Acute Attack & Symptoms & No Symptoms & Total \\
\hline$\ldots$ & $\ldots$ & $\cdots$ & $\cdots$ & 21 & 10 & 8 & 39 \\
\hline Pilocarpine & .. & $\cdots$ & $\cdots$ & \multirow{2}{*}{29} & \multirow{2}{*}{$\left.{ }^{18}\right\} 25$} & \multirow{2}{*}{$\left.\begin{array}{l}67 \\
16\end{array}\right\} 83$} & \} 137 \\
\hline Eserine & $\ldots$ & ... & ... & & & & 34 \\
\hline Total ... & .. & $\cdots$ & $\ldots$ & 50 & 35 & 91 & 176 \\
\hline
\end{tabular}

The results of treatment are shown in Table IV (overleaf) under three headings. The miotic-treated groups have not been further subdivided according to the strength of miotic, first, because patients tend to be given weaker miotics the longer they survive without symptoms, and secondly, because if a patient has the anatomical and vasomotor pecularities which predispose him to another acute attack, a routine miotic two or three times a day will often not prevent it occurring. There are patients in this series who have had an acute attack despite the use of 1 per cent. eserine.

Table IV shows that, of 39 untreated cases, 31 (78 per cent.) had an acute attack (21) or prodromal symptoms (10) in the second eye. In another series of nineteen untreated cases described by Winter (1955), seventeen ( 89 per cent.) developed symptoms.

The apparent difference in the incidence of prodromal symptoms in patients treated with pilocarpine and with eserine is not statistically significant, being due to the difference in size between the two series. 
TABLE IV

PERCENTAGE RESULTS

\begin{tabular}{|c|c|c|c|c|c|c|c|c|}
\hline \multirow{2}{*}{\multicolumn{6}{|c|}{ Treatment }} & \multirow{3}{*}{$\begin{array}{c}\begin{array}{c}\text { No. of } \\
\text { Cases }\end{array} \\
39\end{array}$} & \multicolumn{2}{|c|}{ 2nd Eye Involved } \\
\hline & & & & & & & \multirow{2}{*}{$\frac{\text { No. }}{31}$} & \multirow{2}{*}{$\frac{\text { Per cent. }}{78\left\{\begin{array}{l}54 \text { Acute Attacks } \\
24 \text { Symptoms }\end{array}\right.}$} \\
\hline Nil & $\ldots$ & $\cdots$ & $\ldots$ & $\cdots$ & $\ldots$ & & & \\
\hline Pilocarpi & & $\cdots$ & $\cdots$ & $\cdots$ & $\cdots$ & 103 & 36 & $34\left\{\begin{array}{l}17 \text { Acute Attacks } \\
17 \text { Symptoms }\end{array}\right.$ \\
\hline Eserine & $\cdots$ & $\cdots$ & $\cdots$ & $\cdots$ & $\cdots$ & 34 & 18 & $53\left\{\begin{array}{l}32 \text { Acute Attacks } \\
21 \text { Symptoms }\end{array}\right.$ \\
\hline Total & $\ldots$ & ... & $\ldots$ & $\ldots$ & ... & 176 & 85 & 48 \\
\hline
\end{tabular}

On the other hand, the difference between treated and untreated patients who developed symptoms is highly significant.

Hence, although miotics will not prevent the onset of acute or subacute symptoms in the second eye, they may in some cases convert a potential acute attack into a chronic closed-angle glaucoma.

The 85 patients who had another acute attack or "prodromal symptoms" were examined to see if there was any difference in the time of onset of symptoms as between treated and untreated cases (Table V).

TABLE V

RESULTS, BY LENGTH OF FOLLOW-UP

\begin{tabular}{cc|c|c|c|c}
\hline $\begin{array}{c}\text { Length of } \\
\text { Follow-up } \\
\text { (yrs) }\end{array}$ & \multicolumn{2}{|c|}{ Symptoms } & \multicolumn{2}{c}{ No Symptoms } \\
\cline { 2 - 5 } & No Miotic & Miotic & No Miotic & Miotic \\
\hline $\begin{array}{cc}\text { Up to } 5 & \ldots\end{array}$ & 20 & 47 & 2 & 53 \\
\hline $6-10$ & $\ldots$ & 7 & 6 & 4 & 20 \\
\hline $11-15$ & $\ldots$ & 1 & & 2 & 5 \\
\hline $16-20$ & $\ldots$ & 2 & 1 & & 4 \\
\hline $20+$ & $\ldots$ & 1 & & & 1 \\
\hline Total & $\ldots$ & 31 & 54 & 8 & 83 \\
\hline
\end{tabular}

Table VI (opposite) sets out the same information in slightly different fashion. The percentage of patients developing symptoms diminishes as time goes on, which seems to suggest that the longer a patient survives without trouble in the second eye the less likely it is to develop.

On the other hand, one patient in this series had an acute attack in the second eye 32 years after that in the first. She had had no treatment and had not appeared for follow-up during this period. The average period which elapsed before 
TABLE VI

\begin{tabular}{ccc|cc|c|c}
\hline \multicolumn{2}{c|}{$\begin{array}{c}\text { Length of History } \\
\text { (yrs) }\end{array}$} & Symptoms & No Symptoms & $\begin{array}{c}\text { Percentage with } \\
\text { Symptoms }\end{array}$ \\
\hline Up to 5 & $\ldots$ & $\ldots$ & $\cdots$ & 67 & 55 & 55 \\
\hline $6-10$ & $\ldots$ & $\cdots$ & $\cdots$ & 13 & 24 & 38 \\
\hline $10+$ & $\ldots$ & $\cdots$ & $\cdots$ & 5 & 12 & 29 \\
\hline
\end{tabular}

symptoms developed in the second eye in untreated patients was 5.7 years; in those treated with eserine it was 3.5 years, and in those on pilocarpine it was 3.7 years. There is no statistically significant difference between these groups, since there were only 39 untreated cases four of which took more than 15 years to develop symptoms, while the treated cases number 137.

The average period which elapsed before symptoms developed, taking treated and untreated cases together, was $4 \cdot 25$ years.

Table VII shows in some detail the seven cases which had a prophylactic operation in the second eye. They form a small series but their record is good.

The first five patients (one peripheral iridectomy and four trephines) have open angles with normal tension and normal optic discs. They have remained symptomfree up to now, and there seems no reason for supposing that they will not remain so.

The last two patients (both trephines) are just beginning to develop trouble after 12 and 24 years respectively.

TABLE VII

PROPHYLACTIC OPERATIONS TO THE SECOND EYE

\begin{tabular}{llll|ll|l}
\hline \multicolumn{3}{c|}{ Prophylactic Operations } & & Numb & \multicolumn{2}{|c}{$\begin{array}{c}\text { Duration of Trouble-Free Period } \\
\text { (yrs) }\end{array}$} \\
\hline Peripheral Iridectomy & $\ldots$ & $\ldots$ & $\cdots$ & 1 & 3 \\
\hline Trephines & $\ldots$ & $\ldots$ & $\ldots$ & $\ldots$ & 4 & $6,6,10$, and 11 \\
\hline & & & 1 & $12 \rightarrow$ peripheral anterior synechiae $\mathbf{T}+$ \\
\hline
\end{tabular}

The patient with the 12-year history has an angle that is almost totally closed by peripheral anterior synechiae. As he has been symptom-free for so long it is almost certain that most of these date from his operation. There was probably delay in the re-formation of the anterior chamber, which is unavoidable in a proportion of cases undergoing a filtering operation. It is suggested that he is suffering from one of the defects of a trephine. His tension began to rise, and he has now had a further filtering operation.

The patient with the 24-year history still has an open angle, but is just beginning to develop cupping of the disc. It seems reasonable to suggest that this patient is beginning to develop simple glaucoma. 


\section{Discussion}

The prognosis for the second eye may be summarized as follows:

(1) The fellow eye may not be glaucomatous, and in a few cases may never become so, but only constant surveillance will tell us this. If in any given case the eye is not going to become glaucomatous the instillation of miotics is a waste of time, although it would be a bold man who would assert this in the individual case.

(2) The eye may become glaucomatous at a later date, as did the majority in this series. Miotics are not a sure guard against this development, and in 29 cases did not even prevent a second acute attack. In 25 other cases symptoms of chronic angle-closure have set in in spite of miotics; many of these cases are apparently controlled on stronger doses of miotics, but how long they will remain so only time will tell. It seems likely that these patients if they live long enough, will either develop cupping of the disc through impaired filtration, or suffer the crisis of an acute or subacute attack.

(3) The eye may already have incipient glaucoma as shown by symptoms of pain, blurred vision, and haloes, or by positive provocative tests. Many patients with positive provocative tests have noticed no symptoms and are fortunate in having had their trouble diagnosed in this way. More cases would almost certainly be found to have glaucoma were a test of 100 per cent. reliability available to us.

(4) The eye may be undergoing an acute or subacute attack when the patient is first seen.

There seems, then, to be a good case for applying provocative tests to the second eye even when it is apparently normal clinically. The tests also help in assessing whether a manifest chronic closed-angle glaucoma may be partially controlled by a miotic at any given time.

There seems to be a better case for undertaking a peripheral iridectomy at any rate in younger patients, and in those whose occupation takes them away from surveillance for long periods. This operation is subject to fewer complications than any other glaucoma procedure. Properly done it should check the progress of peripheral iris bombé, peripheral anterior synechiae, and trabecular blockage, which lead eventually to cupping of the disc, and may at any time be interrupted by an acute attack.

\section{Summary}

(1) 200 patients who had suffered an attack of acute closed-angle glaucoma have been examined to discover the fate of the fellow eye.

(2) Excluding seven cases who had undergone a prophylactic operation, 53 per cent. developed symptoms in the other eye. In 35 per cent. the "symptoms" comprised another acute attack. 
(3) There was no significant difference in the time taken to develop trouble in the second eye between patients treated with miotics and those who had no treatment.

(4) The second eye became involved after an average interval of 4.25 years regardless of treatment.

(5) The use of provocative tests for closed-angle glaucoma in symptomfree patients is re-emphasized.

(6) It is suggested that peripheral iridectomy is a safer guard against trouble than miotic therapy.

I acknowledge with pleasure Sir Stewart Duke-Elder's advice and criticism in the preparation of this paper.

\section{REFERENCES}

Barkan, O. (1937). Amer. J. Ophthal., 20, 1237.

(1938). Ibid., 21, 1099.

(1939). Arch. Ophthal. (Chicago), 21, 331.

(1954a). Amer. J. Ophthal., 37, 332.

(1954b). Ibid., 37, 504.

BENNETT, G. (1955). A.M.A. Arch. Ophthal., 54, 637.

Chandler, P. A. (1952). Ibid., 47, 695.

and TrotTER, R. R. (1955). Ibid., 53, 305.

WINTER, F. C. (1955). Amer. J. Ophthal., 40, 557. 